Session 2325

\title{
Multidisciplinary Multilevel Functionally-Managed Student Design in the SAE Mini-Baja Project
}

\author{
Andrew N. Vavreck, Catherine G. Latterell, Michael R. Lucas \\ Penn State University, Altoona College
}

\begin{abstract}
In order to heed the call in engineering education to provide richer learning environments, in which engineering students develop critical skills to work effectively on teams with individuals from other fields, we need to encourage development of multidisciplinary, multilevel learning experiences in which students play lead roles. The Society of Automotive Engineers (SAE) Mini-Baja competition project at Penn State Altoona is one example of how faculty and students have been addressing this need. The project is structured as a functional organization, with students from many disciplines (engineering, engineering technology, business, English and art) engaged in supporting vehicle design, development and testing efforts. The student team, consisting of freshmen through seniors, are grouped by functional area (vehicle subsystem design, documentation, marketing, fabrication and testing) and coordinated by a "directorate" of upperclassmen. Students earn college credit for some of the activities, but the majority of the effort is on a volunteer basis. The project provides an excellent environment for crossdisciplinary learning, as well as team and project management skill development, and is an efficient way to carry on a major design effort. In addition, the project provides engineering research opportunities for one of the authors. The paper discusses the project organization in detail, and discusses the means and limitations of involving faculty and students from various disciplines in a broad integration of teaching, service to the profession and community, and research.
\end{abstract}

\section{Introduction}

Altoona College is a regional campus of The Pennsylvania State University, located in southcentral Pennsylvania. The campus serves a regional, statewide, national and international clientele, with about 3,800 students in several four-year programs as well as in the first two years of undergraduate instruction for students who will matriculate at the University Park Campus, in University Park, Pennsylvania, 45 miles away. Faculty at Penn State Altoona struggle with the many student issues that confront faculty at any college campus, including adequate technical 
preparation for the profession, apathy, development of teamworking skills and heavy workload. The faculty also deal with their own issues, especially, for those on tenure track, effectively balancing the duties of teaching, service and research. Many educators have addressed the industry-driven desire to help students work more effectively on teams and on projects, including large center-based multidisciplinary efforts involving engineers from different fields, ${ }^{1}$ programs vertically integrated by courses, ${ }^{2}$ classroom-based integration of students within and outside engineering in the sciences, ${ }^{3}$ teaming between business and engineering students in a capstone design course ${ }^{4}$ and graduate product design with business and engineering students. ${ }^{5}$ In addition, of course, many cross-disciplinary business and engineering programs and minors in other fields for engineering students are available at many campuses.

A means has been developed at Penn State Altoona to address many of these student and faculty issues simultaneously, in a unique vertically and horizontally integrated, structured learning environment. The project, which centers on one design competition, the Society of Automotive Engineers (SAE) Mini-Baja ${ }^{\circledR}$, is very broad in the range of disciplines involved, relies on a mix of courses developed specifically for the project and work in existing courses to engage students, is provided with an industrial framework and provides faculty research opportunities. The program thus helps students with their development of professional skills in a framework that helps enable faculty to efficiently execute their tenure responsibilities. As such, it might be suggested that the concept would be of special interest to new faculty, who may be looking for a way to efficiently carry out all their duties with an eye to tenure requirements.

\section{SAE Mini-Baja}

The SAE Mini-Baja ${ }^{6}$ is an international competition that pits student teams from around the world against each other in design, construction and testing of an off-road vehicle. The vehicle (Penn State Altoona's 2000 vehicle is shown in Figure 1) is a single-seat, four-wheeled vehicle, powered by a 10 horsepower gasoline engine, which must be designed to be marketable for a 4000-unit production cost of less than $\$ 2,500$. The materials used in the construction, construction techniques, dimensions and arrangements of members in the roll cage and chassis, and other design issues are regulated by strict rules imposed by SAE, safety being a primary concern. Within these constraints, students are free to choose suspension components, chassis shape, body materials, drive train configuration, tires, driver controls and ergonomic features to enhance the appearance and performance of their vehicle. The student teams are scored in a number of categories, including a design report, a safety report, a cost report, and appearance and vehicle performance. Three regional competitions are sponsored by SAE: Mini-Baja Midwest, Mini-Baja East and Mini-Baja West. Penn State Altoona participates in the nearest geographically, Midwest. The on-site part of the competition in Mini-Baja Midwest takes place alternately in southeastern Wisconsin and southwestern Ohio. 


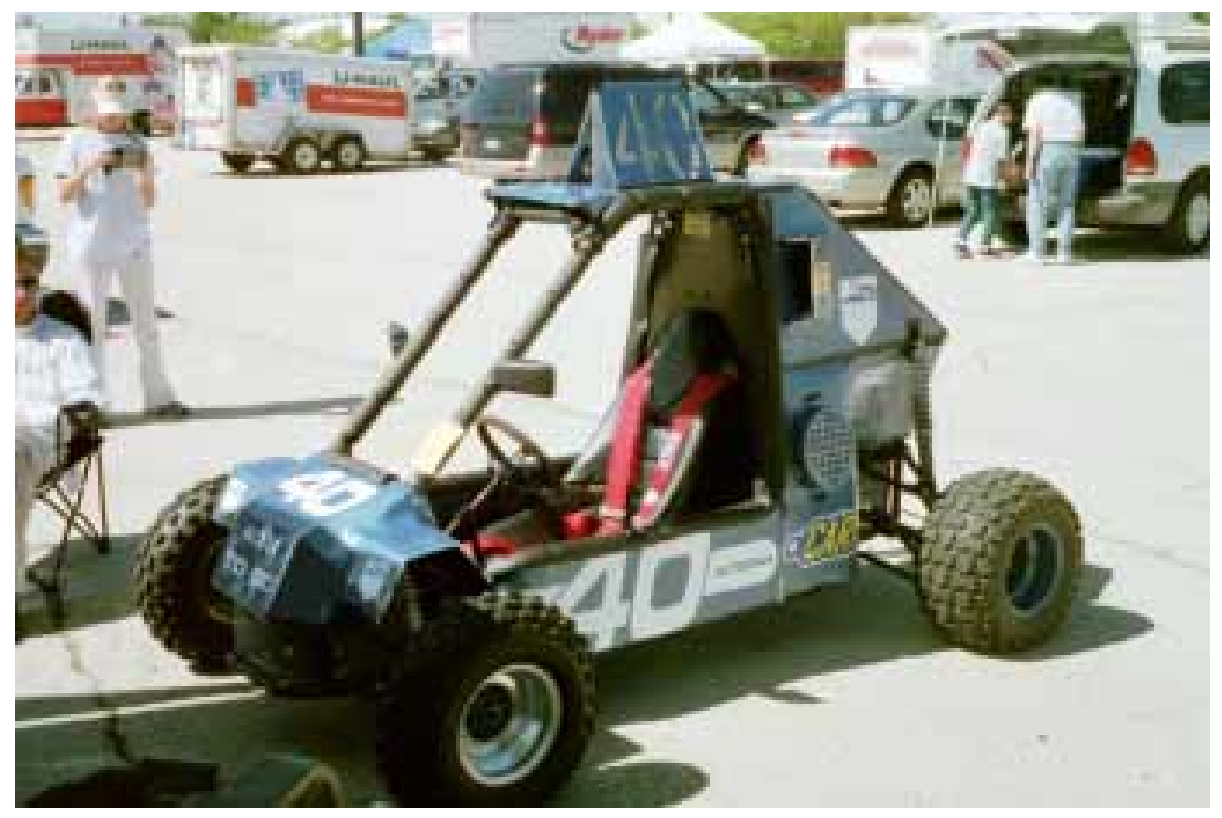

Figure 1: Mini-Baja Vehicle

The on-site competition involves judging by SAE teams on appearance and marketability, structural integrity and other safety issues, acceleration and braking, maneuverability, a skid pull and a four-hour endurance race, on a motocross-style track. Scoring for the three Mini-Baja events is depicted in Figure 2. The 2000 Mini-Baja Midwest, a several-day event in early June, attracted 106 student cars from many states and countries. Penn State Altoona has participated in this competition since 1999.

\section{Project Organization and Operation}

In 1999, the project involved only engineering technology students, mainly seniors, and was nearly an afterthought for the year, getting started only very late in the Fall semester. The team did field a car, but only with much effort by very few students, and with the vehicle completed only at the very last minute, with no time for testing. Consequently, even though the results placed the team's car solidly in the middle ranks of the rookie cars that year, the overall place (62 out of 77 cars) was rather disappointing. In Fall Semester 2000, a decision was made to improve the organization of the project, and to include students and faculty from other areas on campus. It was decided to adopt a functional organization for the project, along the lines of a manufacturing firm, since the object of the competition is to design, manufacture and test a prototype, saleable vehicle. The new "company" organization is shown in Figure 3. 


\begin{tabular}{|l|c|c|c|}
\hline & $\begin{array}{c}\text { MINI BAJA } \\
\text { EAST }\end{array}$ & $\begin{array}{c}\text { MIDWEST } \\
\text { MINI BA.JA }\end{array}$ & $\begin{array}{c}\text { MINI BAJAA } \\
\text { WEST }\end{array}$ \\
\hline STATIC EVENTS & & & \\
\hline $\begin{array}{l}\text { Engineering Design } \\
\text { (Mechanical Design) }\end{array}$ & 200 & 360 & -50 to +100 \\
\hline $\begin{array}{l}\text { Engineering Sales } \\
\text { Presentation }\end{array}$ & - & & 0 to 100 \\
\hline Cost & 150 & 30 & 100 \\
\hline Sallety & -100 to +50 & -100 to +35 & with design \\
\hline DYNAMIC EVENTS & & & \\
\hline Acceleration & 50 & 40 & $+j-100$ \\
\hline Braking & 50 & 40 & \\
\hline Top Speed & 50 & 40 & \\
\hline Land Maneuverability & 100 & 40 & $+j-100$ \\
\hline Water Maneuverability & 100 & & \\
\hline Suspersion \& Traction & 100 & & \\
\hline Chain Pull & 100 & & \\
\hline Sled Pull & & 40 & \\
\hline Hill Climb & & 40 & $0-100$ \\
\hline Endurance & 400 & 225 & 400 \\
\hline TOTAL POINTS & 1,350 & 890 & 1,000 \\
\hline
\end{tabular}

Figure 2: Mini-Baja Scoring

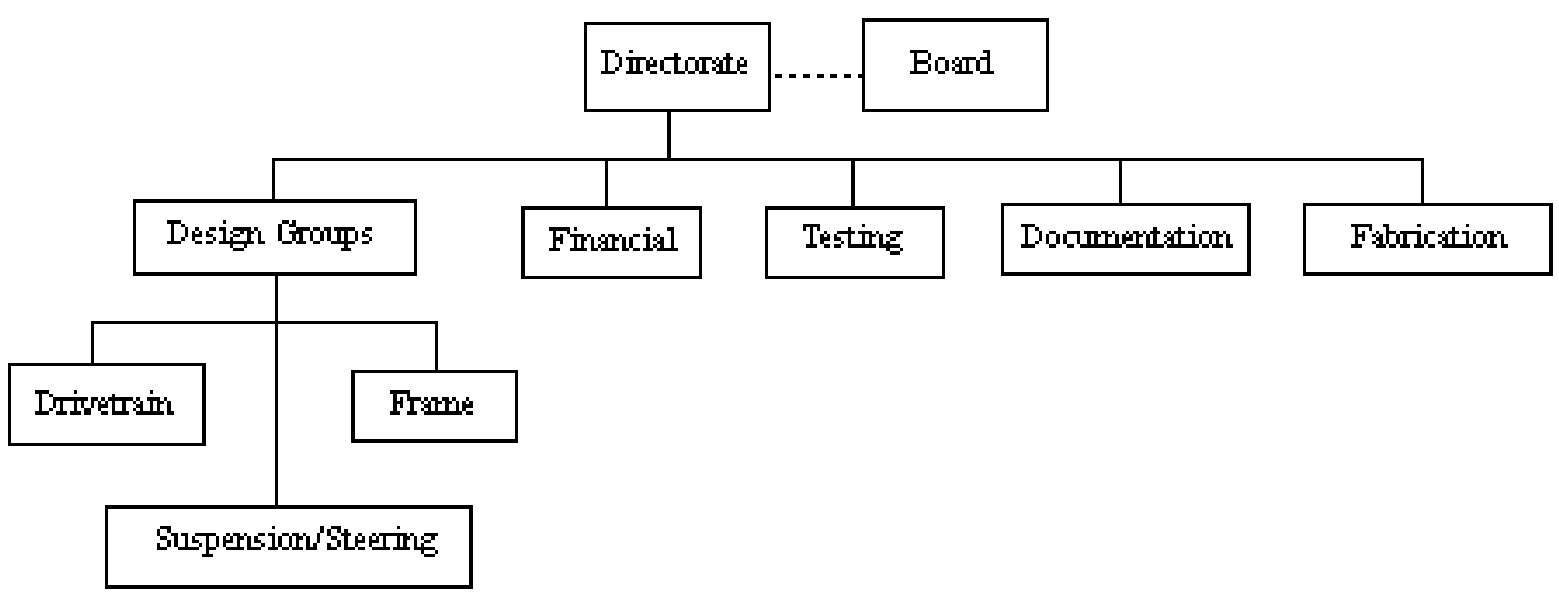

Figure 3: Mini-Baja Project Organization

Groups deal with design of vehicle subsystems, finance (fundraising, cost analysis and cost reporting), fabrication, documentation and testing. The groups are generally staffed by younger students, sophomores and freshmen, under the leadership of engineering technology upperclassmen. The "directorate" of the company are the four officers of the Penn State Altoona ASME Student Section, and they are advised by a "board" of faculty, in particular by their Student Section faculty advisor (author Vavreck). Students involved in the groups come from a broad range of majors, including engineering, engineering technology, art, English and business, although most of the students involved since the inception of the project in 1999 have been 
engineering or engineering technology students. The group leaders set their own group agendas, but coordinate their activities with the directors and with each other in regular meetings. The leaders in the directorate work as a management team, but usually one student becomes a de facto overall project leader, while the others among the officers gravitate toward spending more time on one area or another of vehicle development or on other general Student Section activities.

Students are encouraged to follow a design process $^{7}$ for the vehicle as a whole and for subsystems. The methodology is shown in Figure 4. Setting forth the need and design requirements are followed by brainstorming approaches to solve the problem, selection of the best approach through rough performance analysis and weighting and scoring of criteria, feasibility testing of the selected concept, with iteration back to selection if the concept fails the feasibility test, design and testing of components of the prototype, and production of the prototype vehicle. Students use various design tools in their iteration through the design process, including AutoCAD, a student kinematics software application, FOURBAR, which is used as part of coursework, ${ }^{8}$ and Pro/ENGINEER. Group leaders coordinate their individual designs through meetings and sharing of design files with other groups, ensuring compatibility between subsystem designs. Students have access to a projects lab, with substantial quantities of tools and support equipment, in which to design and build the car. (Figure 5).

\section{Courses}

Keeping students engaged throughout the academic year with the project is a problem, and this, along with the goal of involving students and faculty from other programs on campus in a meaningful way, has led to the establishment of several credit-bearing courses involving the project. In addition, in order to attract interest to the project and engage students in projectrelated efforts, several existing courses at the campus have incorporated activities involving the project. 


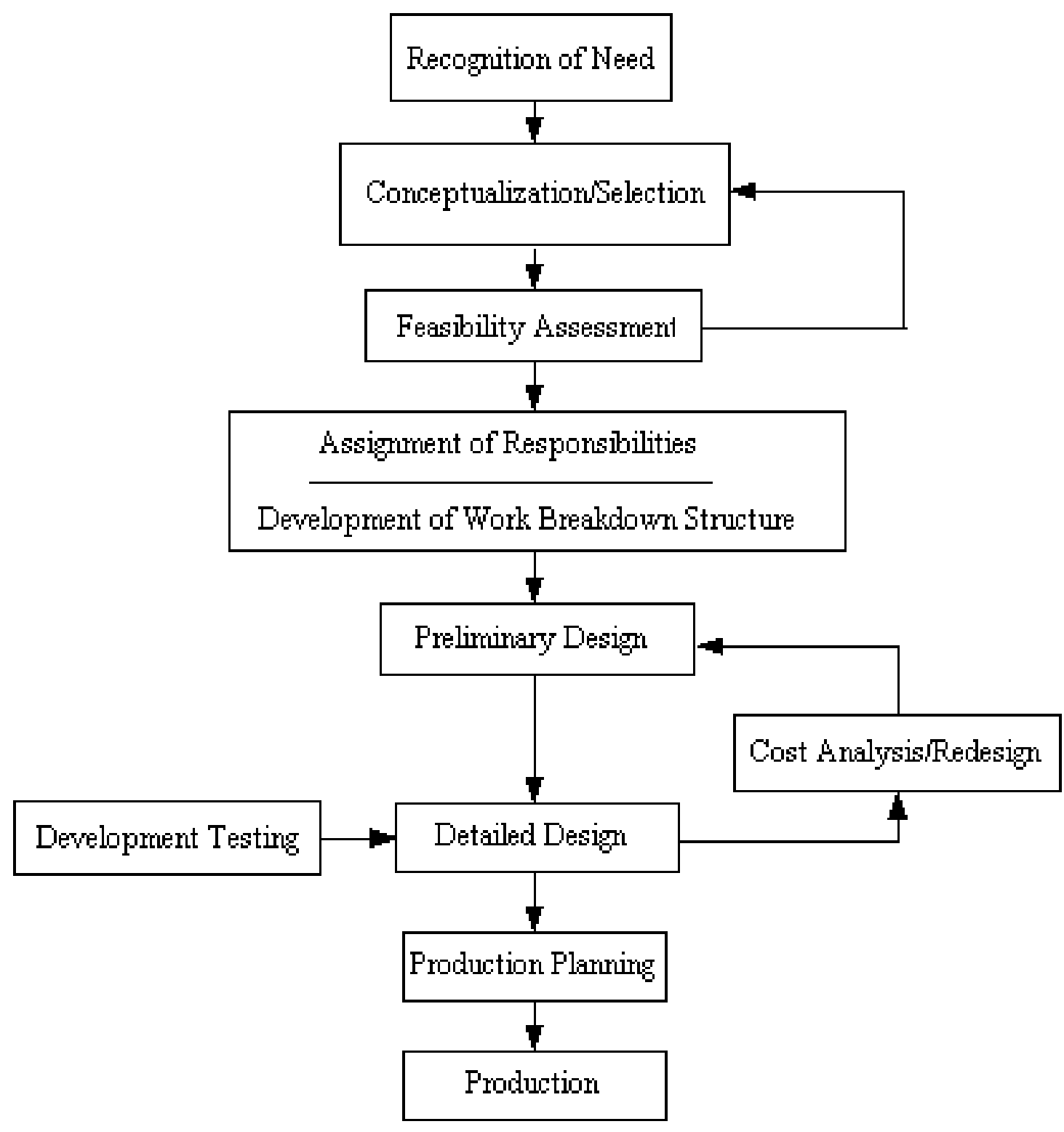

Figure 4: Design Methodology

\section{IV.A. Art Courses}

One of the new courses to be developed was an art course. In the Spring of 2000, a desire was expressed to begin to make the Mini-Baja car's form aesthetically pleasing as well as functional. Consequently, involvement by an instructor from the art program (author Lucas) in the MiniBaja Car Project centered on an attempt to fabricate the outer shell (or body) of the car. In order to provide students the opportunity to investigate body possibilities, a special topics art course, Art 297B, was added to the schedule. The course carried one credit and, for scheduling purposes, officially met by appointment. Three students signed up for the credit, all engineering 


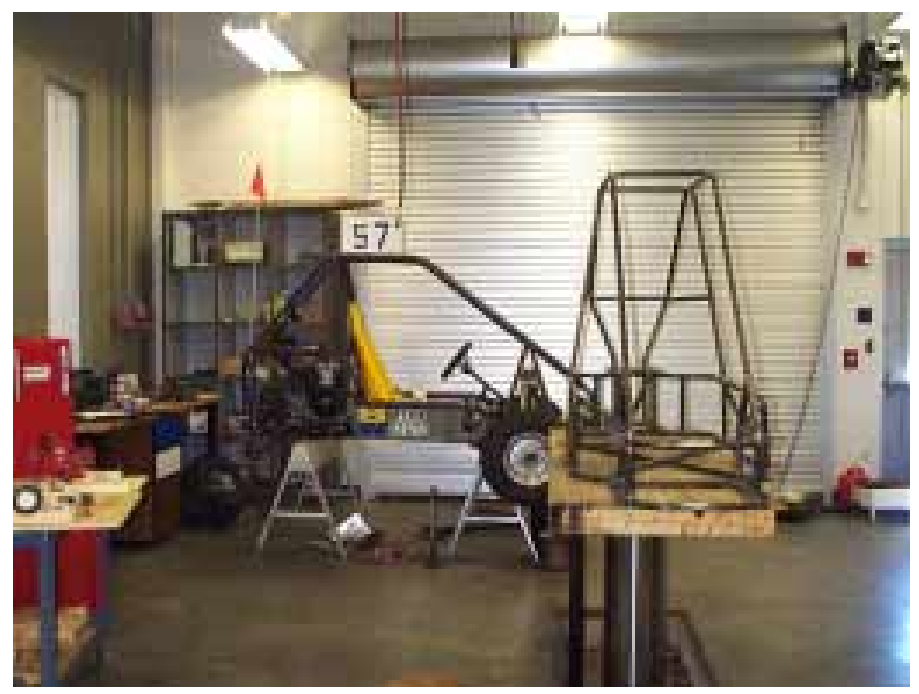

Figure 5: Projects Laboratory

students. The three students and the instructor decided upon times when the team could get together as a group.

One of the most interesting aspects of the attempt was the initial lack of pre-conception. The goal, of course, was to fabricate body parts. How to go about this involved research and experimentation, as no one in the group had any experience in this area. After definitely deciding on fiberglass as structure, the students and instructor assigned themselves tasks of information gathering, acquiring video demonstrations, and materials ordering. Finally, after crucial time had passed, the team began the hands-on work of shaping and building. To put things into perspective, the team was not only designing body parts, it was designing an approach as well.

Several observations of the students' performance in the art course are worth mentioning. First and foremost, as they immersed themselves in the design process, they gained great insights into active problem solving. The students were constantly confronting their imagination and creativity as well as solving issues about materials and techniques. Secondly, their enthusiasm led them to exceed the normal time requirements for earning one credit. Further, they welcomed the responsibility for researching fiberglass materials and processes before beginning.

Several practical hurdles had to be overcome during the project. One, of course, was the unfamiliarity with fiberglass. Another was the budget, which became a complex issue, given that the project spanned administrative areas at the campus. Another problem was facility limitations. The art faculty had real problems securing an area where the team could work undisturbed for adequate lengths of times. Lastly, was accessibility to the vehicle: building and rebuilding the framework of the car was still ongoing at the same time that the team was trying to proceed with the body.

The impact of the car body course on the Mini-Baja Car Project is real but debatable. On one hand, the attempt to make the car have a "finished" look is quite positive. On the other hand, 
owing to this being a first attempt, the body was not as well crafted as could be. To make an analogy to another art form, the course produced a working sketch instead of a finished painting.

In Spring 2001, a new course, Art 30, has been scheduled, that was specifically advertised to engineering technology students. It is a General Education three-credit class. The plan is to make the car-body problem a final project in this course. The reasoning is two-fold. One, more students may become interested in taking the course, given that it fulfills curricular requirements and carries more credits. Secondly, earlier design projects in this course will lead up to the car project. In other words, the class is beginning to pre-conceive the approach a little.

In the final analysis, the collaboration between engineering and art students on the Mini-Baja Car, has been profitable. The profit, however, has so far revealed itself in the design process rather than the product. Further, the students involved have realized, and related to the instructor, how that process transcends engineering and art. That process, with its times of progress and satisfaction, as well as times of set-back and hesitation is common to all fields of creativity. Their experience and realizations are the current fruit of the art collaboration.

\section{IV.B. English Course}

Industry's desire to have employees be better communicators, ${ }^{9}$ the importance of the reports required by the competition and the general desire in the project to have broadly multidisciplinary teams provided incentives to enhance the communication experience of engineering technology students as it relates to the project. To provide students with course credit for the amount of writing required for the competition, a 1-credit English course called Engineering Documentation (English 397A) was established and taught by a member of the English faculty with a background in technical communication. The goal of this course is to help students integrate writing and rhetorical strategies into the heart of their engineering education. One of the most basic concepts of rhetorical theory and writing pedagogy is that success in the writing classroom depends upon the instructor's ability to reproduce for students how writers work in workplace and other settings. To that end, writing courses focus on audience and purpose and the social contexts within which writers work and how these affect the design of their writing. The Mini-Baja project takes these concepts out of the abstract and makes them real. As students draft, revise, and compile the Design, Cost Analysis, and Safety Reports that are submitted as part of the competition, questions naturally emerged from the design contexts that organized their writing. These questions included the following: How can we highlight key features of the design? How can we instill confidence that the design team is capable? How can we persuade the judges that our design is a productive one?

Throughout the process of writing these reports, students came to see the integral role of writing in the design process itself. From the beginning of their work, writing influenced the design. To begin, team leaders record all design decisions, keeping extensive notes, as well as creating graphic representations of their decisions. These notes are read by all team leaders, and became the starting point for many problem-solving sessions. As the team drafted the Design Report, they divided the report into sections that allowed individuals to articulate how the team identified and met specific design challenges related to the Frame, Suspension, Steering, and Drive Train systems of the vehicle. Each writer's section was reviewed by the entire design team. 
Additionally, among the engineering students, one student majoring in English acted as the report editor. This student often raised questions in design meetings that led the team to recognize patterns (productive and unproductive) in their decision-making processes that streamlined both the writing and the design process. By integrating the drafting of the reports into the time spent designing the vehicle, writing became a means or way for students to think through the design process itself.

\section{IV.C. Existing Courses}

The project also involves students through existing technical courses at the campus. In Mechanical Engineering Technology 206 (Dynamics and Machine Elements), students are given class assignments (laboratories) involving several aspects of the vehicle design. Students measure suspension components on an existing vehicle, develop a kinematic model in software and analyze the kinematics and dynamics of the structure. They also investigate a gearbox and analyze a complete vehicle drive train. In Engineering Graphics Technology 114 (Spatial Analysis and CAD), students draw vehicle components in AutoCAD for class assignments. Students in Mechanical Engineering Technology 210W (Product Design) work on assignments involving drive trains and gearing using the vehicle systems as examples. Students in Electromechanical Engineering Technology 440 (Electromechanical Project Design) take on capstone design projects involving the vehicle. As an example of this last, students have designed an adaptive suspension, using magnetorheological dampers, to help control vehicle roll, and a test stand for a magnetorheological brake, with an eye toward the use of such a device in a future four-wheel-drive vehicle. These capstone projects have become an integral part of the research of one of the authors.

\section{Research}

The research interests of author Vavreck focus on applications of magnetorheological (MR) devices and modeling of MR fluid. MR fluid is a suspension of magnetizable particles in oil. When subjected to a magnetic field, the particles polarize and attract each other, forming a structure, and causing the fluid to take on a solid character (Figure 6). The large, rapid (milliseconds) change in mechanical properties, from a paint-like liquid to a solid with the consistency of peanut butter, have led to the development of numerous applications, including brakes, dampers, clutches and lens polishing equipment. Dr. Vavreck's research in part now involves applications of MR devices like dampers (Figure 7) and brakes to vehicles for adaptive suspensions, vibration control and torque transfer. The availability of a test bed, the Mini-Baja car, and the interesting focus the project provides, on off-road vehicle design, have provided an exciting and relevant new research direction. As mentioned previously, student teams have developed test beds (Figure 8) for MR adaptive suspensions (Figure 9) and for MR four-wheeldrive couplings, and the project is ripe with other areas for investigation.

\section{Benefits of the Project}

In the project, students develop skills to work better in teams that are broadly interdisciplinary, a recognized need in industry. ${ }^{10}$ Younger students gain experience sharing duties, working with strangers, going through the four parts of team formation: Forming, Storming, Norming and 
Conforming, ${ }^{11}$ and dealing with time constraints as well as design constraints on a team with a relevant project. Older students, in leadership roles, gain experience in managing people and managing projects. All students involved gain valuable experience in the many areas of technology which must be applied to produce a quality vehicle, including shop techniques, safety, mechanical design and electrical design. Students from disciplines outside engineering and engineering technology gain an opportunity to work alongside technology-based students, to the great benefit of both sides.

Volunteer student projects typically attract a significant number of students at the start, then, through distractions, lack of organization (not having regular meetings or clear objectives or roles, for instance) and competing workload, students drift away from the project, leaving a small group of students, usually classmates and friends, to finish the effort. The Mini-Baja organization Penn State Altoona has developed helps keep students involved for longer, through providing a structured project and class credit for involvement. Students are enthusiastic about the project, eager to find other areas in which to help and eager to learn new skills. A sense of pride about the project has developed, an identity with the effort,

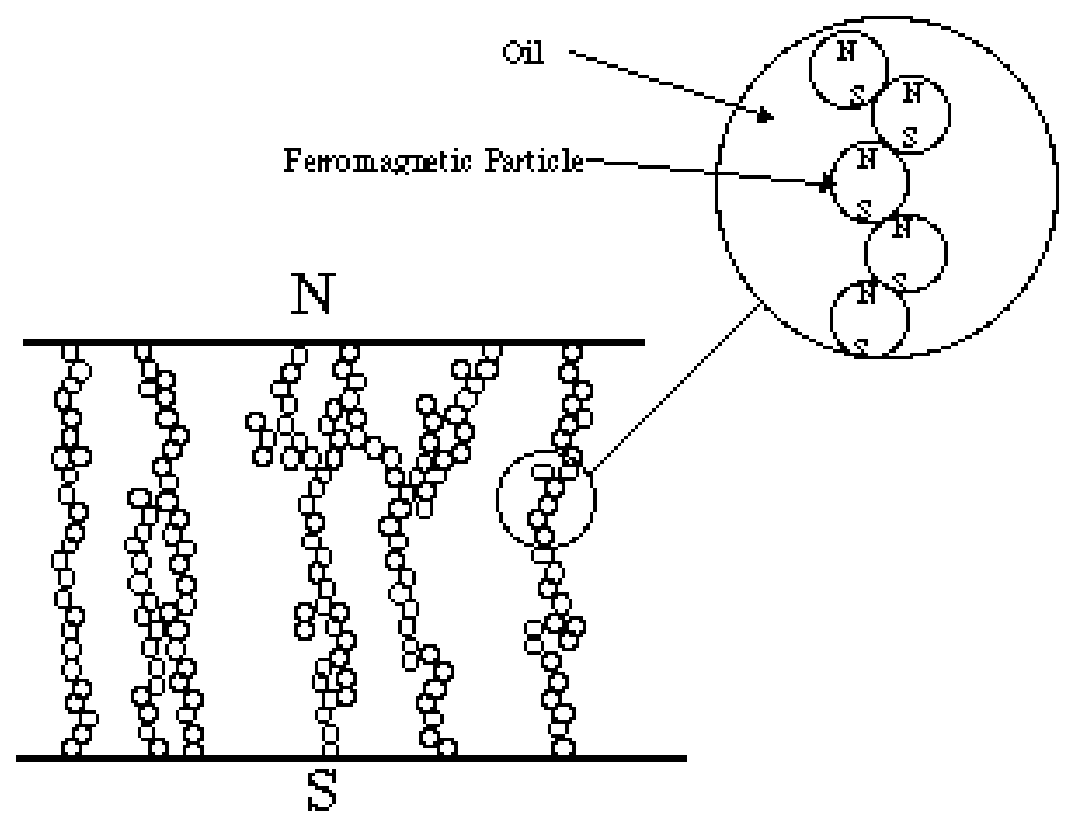

Figure 6: MR Fluid Behavior 


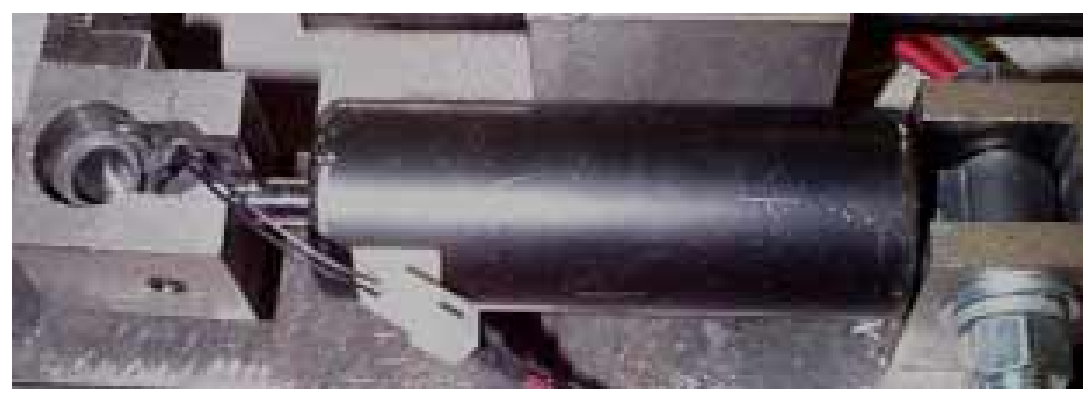

Figure 7: Magnetorheological Damper

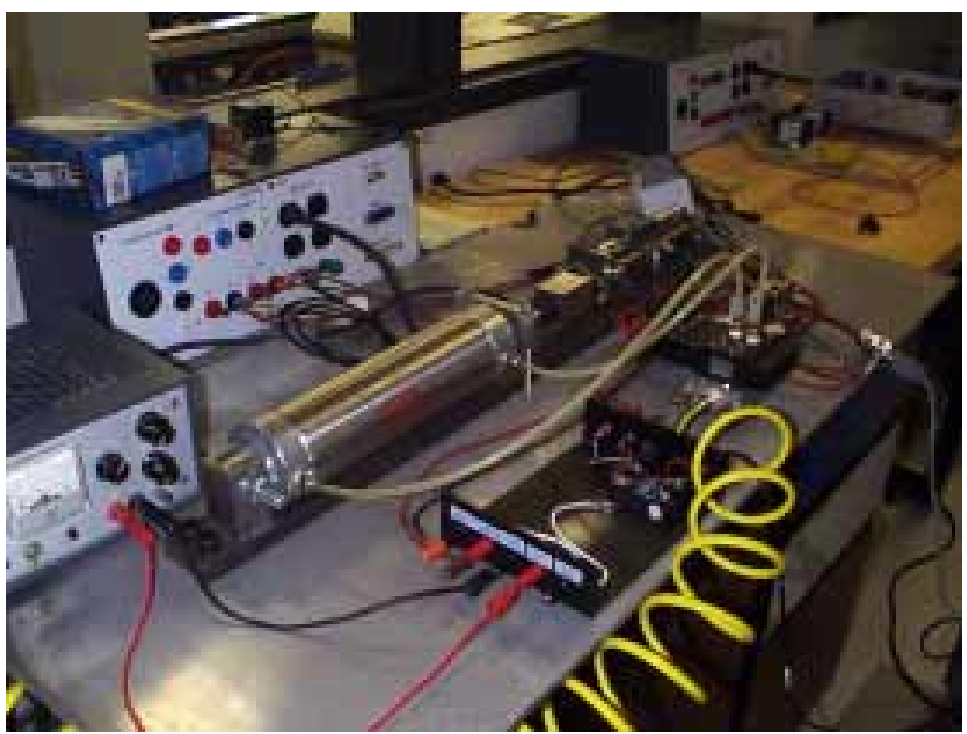

Figure 8: MR Damper Test Bed

much like the identity many employees feel with a company. For instance, Mini-Baja team tshirts are a very popular fundraising item, and are worn proudly by the students.

Faculty gain a great deal from involvement in the project as well, in all three areas in which tenure-track college faculty are expected to excel: service, teaching and research. The opportunity to serve the profession and community is found in several ways: by improving the preparation of students to join the profession; through their own gain of experience and in providing knowledge in areas outside their own fields; and in the interaction the students have with professionals from other fields. Teaching is assisted by the inclusion of exciting, relevant material from the project in classes, turning an abstract exercise into something quite real and of great innate interest to the students involved. In research, one faculty member has modified his research direction to include areas of the vehicle design. The vehicle project and student projects derived from it provide a now-essential part of his research agenda.

One quantifiable benefit in the competition itself was a better placing in the 2000 competition, 61 out of a field of 106 cars, and top honors in the skid pull. A miscalculation in the drive train 
design cost the team substantial acceleration, speed and lap points, otherwise the placement would have been substantially higher, the team believed; the car was much better designed, constructed and tested than the 1999 car.

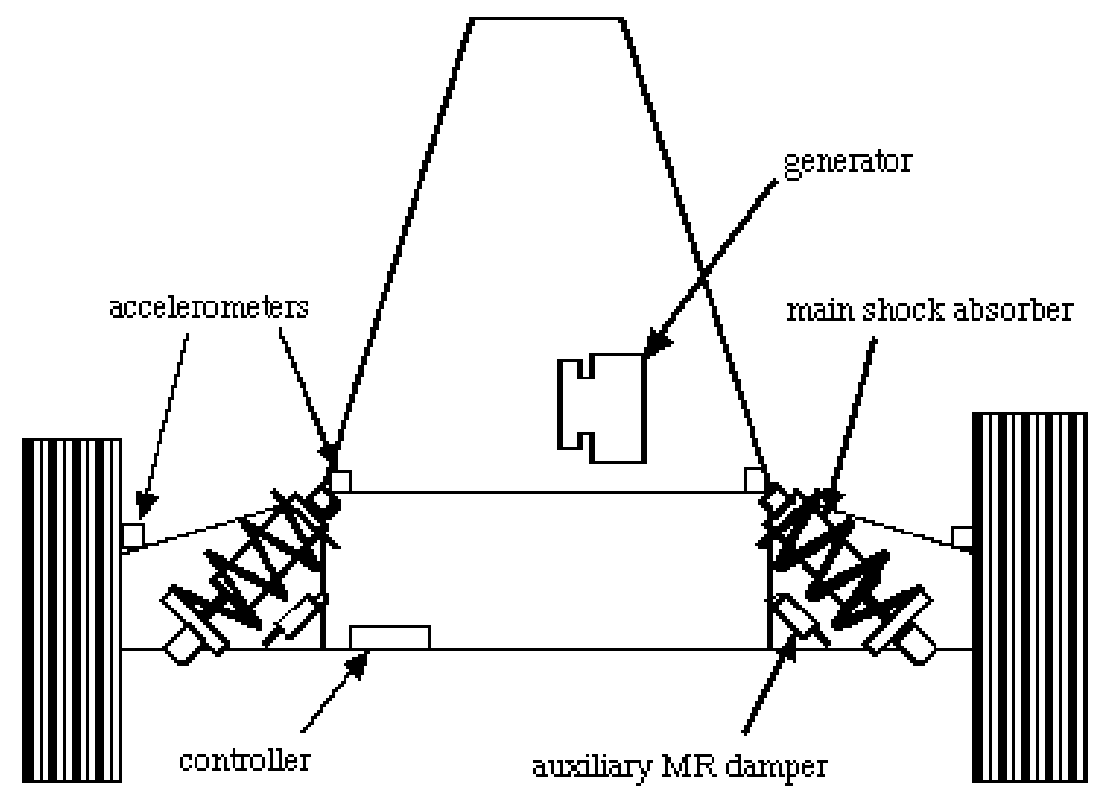

Figure 9: MR Adaptive Suspension

\section{Limitations}

Even with incentives for students including a better organization and some course credit, student workload, and the impact of other work on their ability to contribute to the project was still a source of difficulty in the 2000 competition. Students still tended to drift away increasingly as the holidays approached, as their other workload impinged, and the group leaders, being supervisors only in a simulated sense, had little power to bring the drifters back on track, outside of trying within their own workload constraints to parcel out interesting work and hounding the errant students with shame as the main tool. It was also not nearly as easy to enroll students in one credit special topic courses, which do not satisfy curricular requirements as satisfactorily as three credit courses, and enrollments in these special topics have been somewhat disappointing. The same issue of impinging workload confronted faculty involved in the project, who of course have many other responsibilities, including a heavy teaching load (standard at this undergraduate campus) and other research interests, which particularly impacts those faculty who have not found a way to merge their research interest more closely with the project. Students also had just begun to be trained in the more sophisticated design tools used, most notably Pro/ENGINEER, and are still not presently trained in use of any project management software, which, it is felt, would help the organization stay on track better and would give the students yet another worthwhile experience. The number of students from the other programs, business, art and Engineering, has also not been as high as desired. Faculty learning more about the interactions between students in the different programs, with different motivators and skill sets ${ }^{12}$ is only one of the many reasons to provide an environment for teams with such a broad range of disciplines: 
a more fundamental reason is to provide a diverse learning environment for all the students, who can learn about working with each other in preparation for future teaming on the job.

VIII. Plans

To further help keep the organization running smoothly longer into the academic year, it is planned to develop an elective design course specifically for this project. The course will run in the Fall semester, and would involve the student design groups performing the system and subsystem design in a methodical way, using design tools including Pro/ENGINEER, Pro/MECHANICA and the management tool Microsoft ${ }^{\circledR}$ Project $2000^{\mathrm{TM}}$. Training in this last application will actually be part of EMET 440 beginning in Spring 2001. These applications would be taught to the students either during the first part of the design course or in other workshops or courses. An approach which will be followed in Spring Semester 2001 to help with credit course enrollments and increase the number of students from other programs is to offer students a 3-credit-hour art course (already existing) on three-dimensional sculpture instead of a one-credit course. The course will be slanted, at least to the engineering and engineering technology students who take it, toward vehicle body design and fabrication, and will count as a general education course, which should improve enrollments and student engagement. An English course modification is also being undertaken in Spring 2001, which would have a special section of the required undergraduate writing course, English 202C, a three-credit course, set aside for students who wish to earn more substantial credit for their work on the Mini-Baja reports.

Other than mainly qualitative indications that students are better organized and seem more motivated because of the project, that such an interaction between students in such a relevant way must be good for them, and that faculty appreciate the opportunities it provides, an effort will be made in the future to gather more quantitative data on the results of the effort, especially after the complete structure of the project, with new courses and design tools, is in place. Surveys of students and faculty will be the major source of this data. Of course, future performance in the competition itself will be an indicator as well.

\section{Conclusion}

The Mini-Baja project at Penn State Altoona provides a unique opportunity to involve students and faculty from widely varying disciplines to work together in a design effort. The project fulfills the need to engage students in meaningful team experiences in a rich learning environment, and attempts to overcome some of the obstacles to engaging student attention and interest while providing useful knowledge and assisting in development of useful skills. It also provides a wealth of benefits for faculty to exercise their tenure responsibilities. Conducting a project like the Penn State Altoona Mini-Baja is not only appropriate for small campuses like Penn State Altoona, where a strong engineering technology program exists, teaching is a primary emphasis, and barriers to interdepartmental cooperation are less significant than at large research campuses. The opportunity to integrate very different disciplines centered on a design competition in such a way can be of benefit to faculty and students at larger campuses as well. 
Bibliography

1. Batchelder, M. J., D. F. Dolan and S. L. Iyer, Center for Advanced Manufacturing and Production: Enhancing Engineering Education Through Team-based Multidisciplinary Projects. Proceedings of ASEE Annual Conference, 2000.

2. Larson, D., S. Howell, K. Collier and J. Hatfield, A Four-Year Path to Synthesis: The Junior Interdisciplinary and Vertically Integrated Design Experience. Proceedings of ASEE Annual Conference, 1998.

3. Hoop, B., Hansberry, E. W. and Voland, G. Student-Centered Science Activities in Lay Science Disciplines. Proceedings of ASEE Annual Conference (2000).

4. Aldgridge, M. D. Cross-Disciplinary Teaming and Design. Proceedings ASEE Annual Conference (1998).

5. Durfee, W. K. The New Product Design and Business Development Program: Engineers and Business Students Join With Industry to Create New Products. Proceedings of ASEE Annual Conference (1999).

6. URL: http://www.sae.org/students/minibaja.htm; SAE Collegiate Design Series: Mini-Baja ${ }^{\circledR}$.

7. Ertas, A. and Jones, J. C. The Engineering Design Process, Second Edition. Wiley and Sons (1996).

8. Norton, R. L. Design of Machinery, Second Edition. McGraw-Hill (1999).

9. Longo, B. Bridging Classrooms and Corporations. Proceedings ASEE Annual Conference (1998).

10. Rahman, S., Smith, T. F. and Butler, P. B. Overview and Expansion of Program for Enhanced Design Experience. Proceedings ASEE Annual Conference (2000).

11. Gido, J. and Clements, J. P. Successful Project Management. South-Western College Publishing (1999).

12. Mohan, G. and Pandit, G. M. A Comparison of Business and Technology Students With Respect To Their Choice of Academic Major. Proceedings ASEE Annual Conference (1999).

\begin{abstract}
ANDREW N. VAVRECK
Dr. Vavreck teaches mechanical engineering, mechanical engineering technology, electromechanical engineering technology and business administration courses. His research involves the application of electro- and magnetorheological fluids to adaptive-passive vibration control and power transmission. Dr. Vavreck earned B.S. (Engineering Science), M.S. (Engineering Mechanics) and Ph.D. (Engineering Science and Mechanics) degrees from Pennsylvania State University in 1982, 1988 and 1997, respectively. He is faculty advisor for the Penn State Altoona Student Section of the American Society of Mechanical Engineers and a member of the Society of Automotive Engineers and the American Society for Engineering Education.
\end{abstract}

\title{
CATHERINE G. LATTERELL
}

Dr. Latterell, assistant professor of English at Penn State Altoona, earned advanced degrees in Rhetoric and Technical Communication from Michigan Technological University (M.S. 1992, Ph.D. 1996). She teaches courses in advanced writing, editing, technical communication, and rhetoric--often asking students to examine the impact of technology on communication and their processes of problem-solving.

\section{MICHAEL R. LUCAS}

Michael Lucas is an Assistant Professor of Visual Art at Penn State's Altoona College. Michael received his B.F.A and M.F.A. from The Pennsylvania State University in 1978 and 1981, respectfully. Specializing in the teaching of first year foundation courses, Michael teaches Beginning Drawing and Three Dimensional Design to freshman art majors. His current creative efforts involve pen and ink drawings inspired by nature. His work has been included in numerous national, juried exhibitions in which he has received several awards including, most recently, a purchase award from "Border to Border 7," the Larson National Drawing Competition, at Austin Peay

State University, in Clarksville, Tennessee. 